Research paper

\title{
Risk factors and molecular typing of Toxoplasma gondii isolated from ostriches (Struthio camelus) from a Brazilian slaughterhouse
}

\author{
Rodrigo Costa da Silva ${ }^{\mathrm{a}, *}$, Helio Langoni ${ }^{\mathrm{b}}$ \\ a Department of Pathobiology and Population Medicine, College of Veterinary Medicine, Mississippi State University, 240 Wise Center Drive, 39762 \\ Starkville, MS, USA \\ ${ }^{\mathrm{b}}$ Department of Veterinary Hygiene and Public Health, School of Veterinary Medicine and Animal Science, UNESP Univ. Estadual Paulista, Botucatu, SP, \\ Brazil
}

\section{A R T I C L E I N F O}

\section{Article history:}

Received 8 April 2016

Received in revised form 31 May 2016

Accepted 1 June 2016

\section{Keywords:}

Toxoplasma gondii

Molecular techniques

Genotype

Struthio camelus

Slaughterhouse

Risk factors

Ostrich farms

\begin{abstract}
A B S T R A C T
Toxoplasma gondii has a worldwide distribution with different genotypes reported in animals and humans. The parasite is of great importance to food production and public health, highlighted by the high diversity of hosts, i.e. ostriches. This study aimed to determine the prevalence of $T$. gondii infection in ostriches from a Brazilian slaughterhouse, the genotype, and the associated risk factors. T. gondii antibodies were detected in 38/344 (11.05\%) serum samples using the modified agglutination test using formalin-fixed tachyzoites (MAT-HS); the parasite was isolated from 14/38 (36.84\%) ostrich brain samples using the mouse bioassay; and the DNA was detected from 25/38 (65.79\%), using PCR. In farms, the water tank was considered the main risk factor ( $O R=141.87$; p-value $<0.05)$, and oocysts were detected in 30\% (6/20) in soil of paddocks before animals were slaughtered (1st sampling), and 40\% (8/20) one-year after (2nd sampling) using microscopy and PCR. Non-ostrich fecal samples on the ground resulted negative. Bioassay isolation was confirmed by PCR. All PCR positive samples were sequenced and resulted in $100 \%$ homology to Toxoplasma gondii repetitive DNA sequence (GenBank access number EF648168-1). These samples were also typed through RFLP-PCR using 11 markers: SAG1, SAG2 (5'-3'SAG2 and alt.SAG2), SAG3, BTUB, GRA6, L358, c22-8, c29-6, PK1, Apico and CS3. Two isolates had a complete genotype, typed from the ostrich tissue. In ostrich samples, the parasite load ranged from 19,043 (TgOsBr1, avirulent) to 54,829 parasites $\mathrm{mL}^{-1}$ (TgOsBr2, virulent) using qPCR, whereas soil samples ranged from 11 to 2,275 parasites $\mathrm{mL}^{-1}$. Both typed isolates resulted on atypical clones, one previously reported to cause congenital toxoplasmosis in Brazilian patients (TgOsBr1, ToxoDB \#206). Thus, these findings support the occurrence of $T$. gondii in slaughtered ostriches from Brazil, ostriches as sentinel for environmental contamination with $T$. gondii, the genotypic variability in Brazilian isolates, and the first isolation and genotyping of $T$. gondii from Brazilian slaughtered ostriches.
\end{abstract}

(C) 2016 Elsevier B.V. All rights reserved.

\section{Introduction}

Toxoplasmosis is a worldwide anthropozoonosis caused by an obligate intracellular, apicomplexan parasite, Toxoplasma gondii, which infects warm-blooded hosts, including humans and production animals (Acha and Szyfres, 2003). T. gondii has a felid definitive host and all other warm blooded animals, including ostriches (Struthio camelus), as intermediate hosts (Hill and Dubey, 2013). It causes abortion in several species of economic interest, and is considered an important problem to public health as foodborne

\footnotetext{
* Corresponding author.

E-mail addresses: silva_rcd@yahoo.com.br, rsilva@cvm.msstate.edu (R.C. da Silva).
}

and opportunistic infection for AIDS and cancer patients (Tenter et al., 2000).

It is transmitted by ingestion of sporulated oocysts present in cat feces, tissue cysts in raw or undercooked meat of the intermediate hosts, or via placental transmission. Most reported outbreaks in humans involve the consumption of raw or undercooked meat, or oocyst-contaminated food and water (Tenter et al., 2000). It is known that the prevalence of $T$. gondii in birds, mainly chickens, who eat food direct from the ground is a good indicator of the environmental contamination by $T$. gondii oocysts, and increases the risk of transmission to humans (Ruiz and Frenkel, 1980; CasartelliAlves et al., 2015; Dubey et al., 2016). The same holds true for ostriches, but there are few studies focused on T. gondii prevalence in this species (Dubey et al., 2000; Martínez-Díaz et al., 2002; Hove 
and Mukaratirwa, 2005; Contente et al., 2009; Almeida et al., 2013; El-Madawy and Metawea, 2013).

$T$. gondii isolates have been considered a single species without geographical boundaries. However, while the parasite population is fairly homogenous in parts of the world, in South America there is a greater genotypic diversity, with recombinant genotypes and atypical alleles widely reported. The parasite has been isolated and typed from humans (Carneiro et al., 2013; Wang and Shen, 2013) and several animal species, i.e., goats (Cavalcante et al., 2007) and sheep (Da Silva et al., 2011; Maciel et al., 2014) from Brazil, dogs (Dubey et al., 2007) and cats from Colombia (Dubey et al., 2006a), chicken from Nicaragua (Dubey et al., 2006b) and Brazil (Soares et al., 2011), dogs, cats and pigs from China (Li et al., 2015) among others, some of which are used for human consumption.

Few studies have focused on the $T$. gondii prevalence in slaughtered ostriches, and information about the epidemiological aspects, i.e. risk factors, concerning the infection in this species are unknown. In this way, based on the hypothesis that ostriches are usually exposed to atypical genotypes of $T$. gondii and infected cats can be a source of infection to commercial ostriches, the present study aimed to determine both the prevalence and risk-factors involved in Toxoplasma infection at the farms and in ostriches reared for human consumption and slaughtered in São Paulo State by the detection of specific antibodies, the mouse bioassay, and molecular typing.

\section{Material and methods}

The present study was conducted in one slaughterhouse and four ostrich farms in São Paulo State, Brazil. The samples were sent to the laboratories for serological testing, mouse bioassay, parasitological and molecular testing. The Ethics Committee in Animal Use from the University approved this study (149/2009-CEUA).

\subsection{Sampling}

Epilnfo 3.5.1 software (CDC, 2002) was used to determine the minimum number of samples $(\mathrm{n})$ needed by using $14.36 \%$ as the expected prevalence (Contente et al., 2009)ñ significance level of $5 \%(\alpha)$, confidence level of $95 \%$, and error limit of $5 \%$; based on this, 294 was the minimum number of samples needed, but 344 animals were sampled. From these, 246 (71.51\%) were male and 98 (28.49\%) female. In addition, 148 (43.02\%) animals were reared on Farm \#1, 99 (28.78\%) on Farm \#2, 57 (16.57\%) on Farm \#3, and 40 (11.63\%) on Farm \#4; all farms are located in São Paulo State (SP).

Blood and brain samples were collected from ostriches from a slaughterhouse in Campinas region, SP. Blood samples were centrifuged at $1600 \mathrm{~g}, 10 \mathrm{~min}$, and the serum samples were tested for T. gondii antibodies; brain samples from seropositive animals were bioassayed in mice for isolation of the parasite, and the parasite DNA was tested using molecular techniques.

Soil and non-ostrich fecal samples were collected from five randomly selected paddocks at each farm in two samplings (1st sampling, before slaughterhouse sampling; 2 nd sampling, one year after the 1 st sampling). The number of paddocks ranged from 20 to 35 per farm. The samples were assayed using the Sheater flotation technique, and tested for $T$. gondii oocysts using microscopy, mouse bioassay and molecular techniques. Non-ostrich fecal samples were collected when found, whereas the soil samples ( $250 \mathrm{~g}$ ) were obtained from five equidistant points inside each paddock where animals were reared. Soil samples were collected $5-10 \mathrm{~cm}$ depth, $45^{\circ}$ inclination, and immediately stored at $4{ }^{\circ} \mathrm{C}$ until use. All positive samples were molecular typed for 11 genetic markers, and sequenced.
An epidemiological questionnaire was applied to the handlers from each farm to determine the risk factors associated with the occurrence of the T. gondii infection in the sampled animals.

\subsection{Serological tests}

Serum samples were tested for $T$. gondii antibodies by the modified agglutination test (MAT) using formalin-fixed tachyzoites, HS antigen (Desmonts and Remington, 1980), and methanol-fixed tachyzoites, AC antigen (Thulliez et al., 1986; Dannemann et al., 1990), using a cut-off titer of 8 for both tests. HS/AC results were matched to patterns published by Dannemann et al. (1990) and Montoya et al. (2007) to determine the stage of infection (acute, intermediate or chronic) of each animal at the moment of slaughter.

\subsection{Oocyst detection}

The soil and non-ostrich fecal samples were tested for the presence of $T$. gondii oocysts according to the Sheater flotation technique (Sheater, 1923), with the following modifications. For soil samples of each farm, $5 \mathrm{~g}$ of each equidistant point inside each paddock were pooled and run in five replicates. The replicates were pre-diluted in $50 \mathrm{~mL}$ ultrapure water, homogenized on a stir plate, filtered in a sterilized mesh sieve filter and centrifuged at $1500 \mathrm{~g}, 7 \mathrm{~min}$. The supernatant was discarded and $10 \mathrm{~mL}$ of ultrapure water was added to the pellet. This suspension was mixed to $50 \mathrm{~mL}$ Sheater flotation solution (sucrose) and centrifuged at $600 \mathrm{~g}$, $3 \mathrm{~min}$, and was kept resting for $3 \mathrm{~h}$. Finally, $5 \mathrm{~mL}$ of supernatant was mixed with $80 \mathrm{~mL}$ of ultrapure water, centrifuged at $1500 \mathrm{~g}, 7 \mathrm{~min}$, and the supernatant discarded. The resulting pellet was suspended in $5 \mathrm{~mL}$ of ultrapure water.

For non-ostrich fecal samples, $10 \mathrm{~g}$ were weighed, added to $40 \mathrm{~mL}$ Sheater flotation solution (specific gravity 1.28 ) in a $50 \mathrm{~mL}$ centrifuge tube and filtered through gauze to another tube. Each sample was evenly divided into five $10 \mathrm{~mL}$ samples, and each vial was individually centrifuged at $1180 \mathrm{~g}, 10 \mathrm{~min}$. Each supernatant was added to $40 \mathrm{~mL}$ ultrapure water and centrifuged again. After decanting the supernatant, all 5 pellets were mixed to $2 \%$ sulfuric acid, aerated on a shaker for 7 days at room temperature $\left(20-22^{\circ} \mathrm{C}\right)$ and then stored at $4{ }^{\circ} \mathrm{C}$ until analysis (Dubey, 1995).

All replicates were individually and pool analyzed via light microscopy at $400 \times$ magnification (Carl Zeiss, The Netherlands), for $T$. gondii oocyst-like structures. For pooled samples, the replicates were mixed, centrifuged at $1500 \mathrm{~g}, 10 \mathrm{~min}$, suspended in $8 \mathrm{~mL}$ ultrapure water, and re-analyzed. Samples were tested for the presence of T. gondii DNA using molecular techniques (Freyre et al., 1989). The differentiation among Toxoplasma, Hammondia, Neospora and Sarcocystis genus was also performed using molecular methods (Da Silva et al., 2009).

\subsection{Mouse bioassay}

Ostrich brain samples from all animals that were seropositive for MAT-HS, as well as positive soil and non-ostrich fecal samples for microscopy, were bioassayed in 30-day-old Swiss albino mice. Each brain tissue $(25 \mathrm{~g})$ was macerated, diluted $1: 5(\mathrm{w} / \mathrm{v})$ in $0.18 \%$ saline solution containing penicillin $\left(100 \mathrm{mg} \mathrm{mL}^{-1}\right)$ and streptomycin $\left(500,000 \mathrm{U} \mathrm{mL}^{-1}\right)$ and digested by pepsin in acid solution (Dubey, 1998). Twenty-two seronegative ostriches were randomly selected and their tissue samples, and 20 soil samples and nonostrich fecal samples that were negative by microscopy, were also bioassayed. Five mice were bioassayed by s.c. injection with $1 \mathrm{~mL}$ of each digested tissue sample, or $1 \mathrm{~mL}$ of each supernatant obtained by Sheater flotation technique for soil or non-ostrich fecal samples. Three vials of $1 \mathrm{~mL}$ of each sample solution were kept at $-80^{\circ} \mathrm{C}$ for the molecular typing. 
All mice were evaluated for 60 days, receiving food and water ad libitum. The infection was confirmed by visualization of the parasite in the peritoneal fluid or the brain of dead animals, or by the positive results for $T$. gondii antibody detection by MAT-HS in those that remained alive for the entire 60 days (Dubey and Beattie, 1988).

\subsection{Molecular techniques}

The extraction and purification of DNA from ostrich and mice brain samples were carried out by using the illustra tissue and cells genomicPrep Mini Spin Kit (GE Healthcare Life Sciences do Brasil Ltda. ${ }^{\circledR}$, USA), according to the manufacturer's instructions. For the soil and non-ostrich fecal samples (Sheater flotation suspension), the DNA was extracted using the AxyPrep Multisource Genomic DNA Miniprep Kit (Axygen, USA), with some alterations. To induce a thermal shock and destroy the huge wall of the oocysts, the samples were pre-treated at $70^{\circ} \mathrm{C}, 10 \mathrm{~min}$, followed by 3 times at $70^{\circ} \mathrm{C}$, $3 \mathrm{~min}$; the samples were immediately frozen in liquid nitrogen after each heating step. The purity and amount of all products were assessed on a Nanovue spectrometer (GE Healthcare, USA).

PCR was run using TOX4 (5'CGCTGCAGGGAGGAAGACGAAAGTTG-3') and TOX5 (5'-CGCTGCAGACACAGTGCATCTGGATT-3') $(10 \mu \mathrm{M})$ set of primers (Homan et al., 2000). These primers amplify a 200-300 times repetitive 529-bp fragment, AF146527 [Genbank], in T. gondii genome. All results were confirmed by nested- and RFLP-PCR targeting $18 \mathrm{~S}$ rRNA region to confirm $T$. gondii infection and differentiate, if necessary, T. gondii, Neospora caninum, Hammondia hammondi and Sarcocystis spp., as previously described (Da Silva et al., 2009). For 18S rRNA regions, the external (Tg18s48F: 5'-CCATGCATGTCTAAGTATAAGC-3'; Tg18s359R: $5^{\prime}$-GTTACCCGTCACTGCCAC-3'; $25 \mu \mathrm{M}$ ) and internal primers (Tg18s58F: 5'-CTAAGTATAAGCTTTTATACGGC-3'; Tg18s348R: 5'TGCCACGGTAGTCCAATAC-3'; $50 \mu \mathrm{M}$ ) (IDTDNA, USA) were used, as well as the restriction enzymes, AluI and Hhal (first set), and DdeI, MspI and Hpy188III (second set) (New England Biolabs, USA). All products were visualized through electrophoresis in 3\% agarose gel, stained with ethidium bromide, and recorded using a digital Gel-Doc-it system (UVP, USA).

The analytical sensitivities for the detection of the parasite in ostrich brain, mouse brain, and soil and non-ostrich fecal samples were measured by using a suspension of $10^{5}$ tachyzoites $\mathrm{mL}^{-1}$ RH strain in water, $10^{5}$ tachyzoites $\mathrm{mL}^{-1}$ in $20 \%$ ostrich brain suspension, $10^{5}$ tachyzoites $\mathrm{mL}^{-1}$ in $20 \%$ mouse brain suspension and $10^{5}$ tachyzoites $\mathrm{mL}^{-1}$ in soil and non-ostrich fecal suspension after Sheater flotation technique. For this purpose, samples of negative ostrich and mouse brains, as well as soil and non-ostrich fecal samples, not use in this study, were assayed. T. gondii tachyzoites were counted in a hemocytometer. Then, serial dilutions at $10^{6}, 10^{5}$, $10^{4}, 10^{3}, 10^{2}, 10^{1}$ and $10^{0}$ bradyzoites $\mathrm{mL}^{-1}$ of each test sample were obtained. DNA extraction was performed on each dilution of each test sample according to the type of sample, and PCR was performed. Cross-reaction to Echinococcus granulosis, Giardia duodenalis, Plasmodium falciparum, Sarcocystis spp., Trichinella spiralis, Trichomonas vaginalis and Neospora caninum was not found using TOX4 and TOX5 primers during T. gondii PCR according to Homan et al. (2000) and Da Silva et al. (2011).

\subsubsection{Quantification of the parasite load}

The parasite load of each PCR-positive sample was assessed using the quantitative real-time PCR (qPCR). Primers sense (5'-CACAGAAGGGACAGAAGT-3') and antisense (5'TCGCCTTCATCTACAGTC- $\left.3^{\prime}\right)$ were used (0.25 $\mu \mathrm{M}$; 94-bp amplification product) in a double-stranded DNA binding dyebased PCR (SYBR ${ }^{\circledR}$ Green PCR Master Mix, Life Technologies, USA), according to the manufacturer (Edvinsson et al., 2006).
These primers target the same 529-bp repeat element described by Homan et al. (2000) (Toxo-529). All reactions were run in a StepOnePlus ${ }^{\mathrm{TM}}$ Realtime-PCR thermocylcer (Applied Biosystems, USA).

\subsubsection{Genotyping}

Strain typing was performed using 11 genetic markers SAG1, SAG2 (5'-3' SAG2 and alt.SAG2), SAG3, B-TUB, GRA6, c22-8, c292, L358, PK1, Apico and CS3, as previously described (Su et al., 2006; Pena et al., 2008). Marker CS3 was included in the present study to evaluate virulence (Khan et al., 2005). Reference strains (GT1, PTG, CTG, TgCgCa1, MAS and TgCatBr5) were used for reaction controls. The target DNA sequences were first amplified by multiplex-PCR using external primers for all markers, followed by nested-PCR for individual markers for genotyping, as previously described (Su et al., 2006; Pena et al., 2008). All products were visualized through electrophoresis in 2.5 or $3 \%$ agarose gel, depending on the marker, stained with ethidium bromide, and recorded using the digital Gel-Doc-it system (UVP, USA).

\subsubsection{Sequencing}

All positive PCR products for 529-bp repeat element primers were purified using the Centrifugal Filter Units purification kit (Millipore, USA) or ExoStar1-Step (GE Healthcare, USA). The purified products were measured for purity and amount on a Nanovue spectrometer (GE Healthcare, USA) and 1.5\% gel electrophoresis. Sequencing was carried out using an ABI PRISM ${ }^{\circledR} 3100$ Genetic Analyzer (Applied Biosystems, USA). The sequenced products were edited in BioEdit Sequence Alignment Editor 7.0.9.0 and blasted in GenBank database at NCBI (http://www.ncbi.nlm.nih.gov/BLAST).

\subsection{Statistical analysis}

All the data were entered on an Excel spreadsheet. Data were analyzed for normality of distribution by the Kolmogorov-Smirnov test. Depending on the data distribution, mean or median was used, as well as the parametric or non-parametric test.

The serological results were associated with the epidemiological variables of origin (state and municipality), sex, age, breed, and breeding system, using univariate analysis by Chi-square test $\left(\chi^{2}\right)$ and/or Fisher's exact test. Posteriorly, all the variables that were directly related to the ostrich that showed p-value $<0.08$ in the univariate analysis were then included in the logistic regression model by multivariate analysis, excluding the variables that only described the different farms (location where each animal came from). The serological result was considered the dependent variable, positive or negative for $T$. gondii. The statistically significant difference was determined when the results showed $\mathrm{p}$-value $<0.05$ in the univariate and multivariate analysis (Triola, 2005).

In addition, the association of the dependent variable "weight" between the total sampled and positive sampled animals was analyzed by the unpaired $t$-test. The correlation among the distribution of "weight", independent of the farm, and "MAT-HS titers" was calculated by the Spearman correlation coefficient ( $r s)$, as well as between the mouse bioassay and PCR results for each type of sample, and parasitological test and PCR for oocyst detection. All tests were run in Epi Info ${ }^{\mathrm{TM}}$ v.3.5.1 (CDC, 2002) and GraphPad Prism 5.01 software.

\section{Results}

\subsection{T. gondii antibody testing}

The present study detected T. gondii antibodies in 38/344 (11.05\%; CI95\% 8.16-14.80\%) ostriches using MAT-HS, and just $8 / 344$ (2.33\%; CI95\% 1.20-4.52\%) using MAT-AC. For MAT-HS, the 
Table 1

Results of the T. gondii antibody testing, mouse bioassay and molecular techniques.

\begin{tabular}{|c|c|c|c|c|c|c|c|c|c|}
\hline \multirow[t]{2}{*}{ Farm } & \multirow[t]{2}{*}{ Animal } & \multicolumn{3}{|l|}{ Serology } & \multicolumn{3}{|c|}{ Mouse bioassay } & \multicolumn{2}{|c|}{ Molecular techniques } \\
\hline & & Stage of infection & MAT-HS & MAT-AC & Result (n) ${ }^{\mathrm{a}}$ & Death $^{\mathrm{b}}$ & Mortality (\%) & $\mathrm{PCR}^{\mathrm{b}}$ & Parasite load (qPCR) \\
\hline \multirow[t]{15}{*}{ \#1 } & 1 & Chronic & 8 & Negative & Negative (0) & nd & 0.00 & Negative & 0 \\
\hline & 2 & Chronic & 8 & Negative & Negative (0) & 59.80 & 0.00 & Negative & 0 \\
\hline & 3 & Chronic & 8 & Negative & Negative $(0)$ & nd & 0.00 & Negative & 0 \\
\hline & 4 & Chronic & 8 & Negative & Negative (0) & nd & 0.00 & Negative & 0 \\
\hline & 5 & Chronic & 8 & Negative & Negative $(0)$ & nd & 0.00 & Negative & 0 \\
\hline & 6 & Chronic & 8 & Negative & Negative (0) & nd & 0.00 & Negative & 0 \\
\hline & 7 & Chronic & 8 & Negative & Negative (0) & nd & 0.00 & Negative & 0 \\
\hline & 8 & Chronic & 8 & Negative & Negative (0) & 38.00 & 0.00 & Negative & 0 \\
\hline & 9 & Chronic & 8 & Negative & Negative (0) & nd & 0.00 & Negative & 0 \\
\hline & 10 & Chronic & 8 & Negative & Positive (2) & 49.60 & 40.00 & Positive & 79 \\
\hline & 11 & Chronic & 8 & Negative & Positive (2) & 39.60 & 40.00 & Positive & 1,712 \\
\hline & 12 & Chronic & 8 & Negative & Positive (2) & 49.60 & 40.00 & Positive & 700 \\
\hline & 13 & Chronic & 8 & Negative & Positive (2) & 49.60 & 40.00 & Positive & 945 \\
\hline & 14 & Chronic & 8 & Negative & Negative (0) & nd & 0.00 & Negative & 0 \\
\hline & 15 & Chronic & 8 & Negative & Negative (0) & nd & 0.00 & Negative & 0 \\
\hline \multirow[t]{22}{*}{$\# 2$} & 16 & Chronic & 32 & Negative & Positive (2) & 50.67 & 40.00 & Positive & 765 \\
\hline & 17 & Chronic & 16 & Negative & Positive (1) & 41.00 & 20.00 & Negative & 0 \\
\hline & 18 & Chronic & 32 & Negative & Positive (3) & 3.00 & 60.00 & Positive & 2,063 \\
\hline & 19 & Chronic & 256 & 8 & Negative (0) & nd & 0.00 & Positive & 923 \\
\hline & 20 & Chronic & 32 & 8 & Positive (1) & 41.00 & 20.00 & Positive & 453 \\
\hline & 21 & Chronic & 32 & Negative & Negative (0) & nd & 0.00 & Positive & 2,290 \\
\hline & 22 & Chronic & 64 & 8 & Negative $(0)$ & nd & 0.00 & Positive & 1,212 \\
\hline & 23 & Chronic & 64 & 8 & Negative (0) & nd & 0.00 & Positive & 1,467 \\
\hline & 24 & Chronic & 16 & Negative & Positive (1) & 43.00 & 20.00 & Positive & 1,002 \\
\hline & 25 & Chronic & 32 & Negative & Positive (2) & 22.00 & 40.00 & Positive & 1,255 \\
\hline & 26 & Chronic & 32 & Negative & Negative (0) & nd & 0.00 & Positive & 564 \\
\hline & 27 & Chronic & 32 & Negative & Negative (0) & nd & 0.00 & Positive & 520 \\
\hline & 28 & Chronic & 64 & 8 & Negative (0) & nd & 0.00 & Positive & 1,323 \\
\hline & 29 & Chronic & 256 & 8 & Negative (0) & nd & 0.00 & Positive & 1,845 \\
\hline & $30^{\dagger}$ & Chronic & 64 & Negative & Negative (0) & nd & 0.00 & Positive & 19,043 \\
\hline & 31 & Chronic & 16 & Negative & Negative $(0)$ & nd & 0.00 & Negative & 0 \\
\hline & 32 & Chronic & 256 & 8 & Negative (0) & nd & 0.00 & Positive & 2,230 \\
\hline & 33 & Chronic & 16 & Negative & Positive (1) & 41.67 & 20.00 & Positive & 964 \\
\hline & $34^{\ddagger}$ & Chronic & 256 & Negative & Positive (5) & 12.00 & 100.00 & Positive & 54,829 \\
\hline & 35 & Chronic & 32 & Negative & Positive (2) & 41.00 & 40.00 & Positive & 1,424 \\
\hline & 36 & Chronic & 64 & 8 & Positive (3) & 22.00 & 60.00 & Positive & 1,776 \\
\hline & 37 & Chronic & 64 & Negative & Negative $(0)$ & 60.00 & 0.00 & Positive & 990 \\
\hline \#3 & 38 & Chronic & 8 & Negative & Negative (0) & 54.80 & 20.00 & Negative & 0 \\
\hline
\end{tabular}

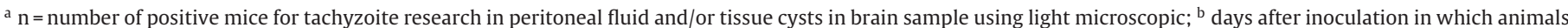

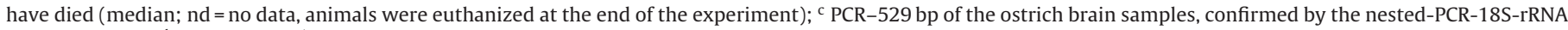
and sequencing; ${ }^{\mathrm{d}}$ parasites $\mathrm{mL}^{-1} ;{ }^{\dagger} \mathrm{TgOsBr} 1 ;{ }^{\ddagger} \mathrm{TgOsBr} 2$.

prevalent titer was 8 (16/38, 42.10\%; CI95\% 27.81-57.90\%), followed by 32 (8/38, 21.05\%; CI95\% 11.13-36.46\%), 64 (6/38, 15.79\%; CI95\% 7.54-30. 35\%), 16 (4/38, 10.53\%; CI95\% 4.30-24.22\%), and 256 (4/38, 10.53\%; CI95\% 4.30-24.22\%), whereas titer 8 was the only titer positive using MAT-AC (Table 1 ). All positive animals presented a chronic stage of the $T$. gondii infection, and a moderate correlation was observed between the MAT-HS and MAT-AC titers ( $r s=0.4379$; p-value <0.0001).

The average weight of the positive animals $(49.09 \pm 5.48 \mathrm{~kg})$ did not differ from the total sampled animals $(50.32 \pm 7.40 \mathrm{~kg})$ $(\mathrm{t}=0.9312$; $\mathrm{p}$-value $=0.3524)$. Particularly to the farms where animals were reared (Farm \#1, 15/148 animals; Farm \#2, 22/99 animals; Farm \#3, 1/57 animals; Farm \#4, 0/40 animals), no significant correlation was observed between the weight and MAT-HS titers $(r s=-0.1545 ; \mathrm{p}$-value $=0.3543)$.

\subsection{Risk factor analysis}

For the univariate analysis, the distance from the paddocks to the feed tanks, the source of water, the presence of non-ostrich feces in paddocks, and the access of rats to the paddocks were considered significant (Table 2), but to the multivariate analysis, just the water tank as a source of water $(\mathrm{OR}=141.87$; $\mathrm{p}$-value $=0.000)$ and the presence of non-ostrich feces in paddocks $(\mathrm{OR}=0.02$; $\mathrm{p}$ - value $=0.001$ ) were significant (Table 3 ). Access of wild animals, i.e. armadillos (Dasypus spp.) and wild cavies (Cavia aperea) to the paddocks was reported in all farms. Also, feed tanks were accessible to other domestic and wild animals.

\subsection{Oocyst detection}

After analyzing the paddocks, independent of the farm, the microscopic analysis of the soil revealed the presence of $T$. gondii oocyst-like structures in 5/20 (25\%) paddocks on the 1st sampling; all of them were confirmed by PCR (100\%). In the 2nd sampling, the positive results in microscopy increased to $9 / 20$ (45\%), but $8 / 9$ (88.89\%) were confirmed by PCR. Farm \#4 had negative results in both samplings (Table 4). All bioassays were negative.

In Farm \#1 and \#2, two and three paddocks, respectively, resulted and remained positive for oocyst research in the 1st and 2nd sampling. Farm \#3 had negative results in all paddocks for the 1 st sampling, but three of them had positive results at the 2 nd sampling. Farm \#4 resulted negative.

\subsection{Bioassay and molecular techniques}

The analytical sensitivity of the PCR-529bp was $10^{0}$ parasite $\mathrm{mL}^{-1}$ in water, ostrich and mouse brain samples, and $10^{1}$ 
Table 2

Association (univariate analysis) between the T. gondii antibody testing (MAT-HS) and the epidemiological variables.

\begin{tabular}{|c|c|c|c|c|c|c|}
\hline Variable & & $\mathrm{N}^{\mathrm{a}}$ & MAT-HS & $\%(\mathrm{CI} 95 \%)^{\mathrm{c}}$ & OR $(\mathrm{CI} 95 \%)^{\mathrm{d}}$ & p-value $e^{e}$ \\
\hline \multicolumn{7}{|l|}{ Gender } \\
\hline & Male & 246 & 26 & $10.6(7.3-15.0)$ & $1.0 ;-$ & - \\
\hline & Female & 98 & 12 & $12.2(7.2-20.2)$ & $1.2(0.6-2.4)$ & $0.70^{g}$ \\
\hline \multicolumn{7}{|c|}{ Ostriches' weight } \\
\hline & $76.30 \geq n>59.90 \mathrm{~kg}$ & 40 & 2 & $4.1(1.3-13.7)$ & $1.0 ;-$ & - \\
\hline & $59.90 \geq n>43.50 \mathrm{~kg}$ & 243 & 29 & $11.9(8.4-16.6)$ & $2.6(0.7-16.6)$ & $0.28^{f}$ \\
\hline & $43.50 \geq n>27.10 \mathrm{~kg}$ & 61 & 7 & $11.5(5.7-21.9)$ & $2.4(0.5-18.0)$ & $0.31^{\mathrm{f}}$ \\
\hline \multicolumn{7}{|c|}{ Distance from the feed tanks (stock's place) to the paddocks } \\
\hline & Far & 97 & 1 & $1.0(0.3-5.6)$ & $1.0 ;-$ & - \\
\hline & Nearby & 247 & 37 & $15.0(11.1-20.0)$ & $16.8(2.3-125.1)$ & $0.00^{\mathrm{g}}$ \\
\hline \multicolumn{7}{|c|}{ Source of water } \\
\hline & Mine & 245 & 16 & $6.5(4.1-10.3)$ & $1.0 ;-$ & - \\
\hline & Water tank & 99 & 22 & $22.2(15.2-31.4)$ & $4.1(2.0-8.2)$ & $0.00^{g}$ \\
\hline \multicolumn{7}{|c|}{ Same source of water for human consumption? } \\
\hline & No & 196 & 23 & $11.7(8.0-17.0)$ & $1.0 ;-$ & - \\
\hline & Yes & 148 & 15 & $10.1(6.3-16.1)$ & $0.9(0.4-1.7)$ & $0.73^{g}$ \\
\hline \multicolumn{7}{|c|}{ Non-ostrich feces in paddocks } \\
\hline & No & 188 & 15 & $8.0(4.9-12.8)$ & $1.0 ;-$ & - \\
\hline & Yes & 156 & 23 & $14.7(10.1-21.2)$ & $2.0(1.0-4.0)$ & $0.06^{\mathrm{g}}$ \\
\hline \multicolumn{7}{|c|}{ Access of rats to the paddocks } \\
\hline & No & 57 & 1 & $1.8(0.4-9.2)$ & $1.0 ;-$ & - \\
\hline & Yes & 287 & 37 & $12.9(9.5-17.3)$ & $8.3(1.1-61.7)$ & $0.01^{\mathrm{g}}$ \\
\hline \multicolumn{7}{|c|}{ Rotation system in the paddocks } \\
\hline & No & 148 & 15 & $10.1(6.3-16.1)$ & $1.0 ;-$ & - \\
\hline & Yes & 196 & 23 & $11.7(8.0-17.0)$ & $1.2(0.6-2.4)$ & $0.73^{g}$ \\
\hline
\end{tabular}

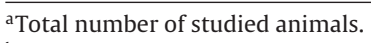

${ }^{b}$ Number of positive animals to the MAT-HS, considering cut-off $=8$.

'Percentage (95\% confidence interval).

dOdds ratio.

${ }^{\mathrm{e}} \mathrm{p}$-value to $\alpha=5 \%$.

${ }^{\mathrm{f}}$ Chi-square test.

gFisher's exact test.

Table 3

Multivariate logistic regression analysis of the epidemiological variables.

\begin{tabular}{|c|c|c|c|}
\hline Variable & $\mathrm{OR}^{\mathrm{a}}$ & CI95\% & p-value ${ }^{c}$ \\
\hline "Water tank" as a source of water & 141.87 & $17.33-1,161.14$ & 0.0000 \\
\hline Presence of non-ostrich feces in paddocks & 0.02 & $0.00-0.13$ & 0.0001 \\
\hline Rats access the paddocks & 0.00 & $0.00->10^{12}$ & 0.9592 \\
\hline Feed tanks nearby the paddocks & $1.23 \times 10^{6}$ & $0.00->10^{12}$ & 0.9647 \\
\hline
\end{tabular}

a Odds ratio.

b $95 \%$ confidence interval.

c $\mathrm{p}$-value for $\alpha=5 \%$.

Table 4

Oocyst detection in farms before slaughterhouse sampling and one-year after.

\begin{tabular}{|c|c|c|c|c|c|c|c|c|c|c|c|c|c|c|c|c|}
\hline \multirow[t]{2}{*}{ Farm } & \multirow[t]{2}{*}{ Sampling } & \multicolumn{3}{|c|}{ Paddock 1} & \multicolumn{3}{|c|}{ Paddock 2} & \multicolumn{3}{|c|}{ Paddock 3} & \multicolumn{3}{|c|}{ Paddock 4} & \multicolumn{3}{|c|}{ Paddock 5} \\
\hline & & LM & PCR & qPCR & LM & PCR & qPCR & LM & PCR & qPCR & LM & PCR & qPCR & LM & PCR & qPCR \\
\hline \multirow[t]{2}{*}{$\# 1$} & $1 \mathrm{st}$ & + & + & 27 & + & + & 212 & - & - & 0 & - & - & 0 & - & - & 0 \\
\hline & 2nd & + & + & 231 & + & + & 128 & - & - & 0 & + & - & 0 & - & - & 0 \\
\hline \multirow[t]{2}{*}{ \#2 } & $1 \mathrm{st}$ & + & + & 11 & - & - & 0 & + & + & 275 & - & - & 0 & + & + & 443 \\
\hline & 2nd & + & + & 986 & - & - & 0 & + & + & 2,275 & - & - & 0 & + & + & 792 \\
\hline \multirow[t]{2}{*}{ \#3 } & $1 \mathrm{st}$ & - & - & 0 & - & - & 0 & - & - & 0 & - & - & 0 & - & - & 0 \\
\hline & 2nd & - & - & 0 & + & + & 379 & + & + & 360 & + & + & 659 & - & - & 0 \\
\hline \multirow[t]{2}{*}{ \#4 } & $1 \mathrm{st}$ & - & - & 0 & - & - & 0 & - & - & 0 & - & - & 0 & - & - & 0 \\
\hline & 2nd & - & - & 0 & - & - & 0 & - & - & 0 & - & - & 0 & - & - & 0 \\
\hline
\end{tabular}

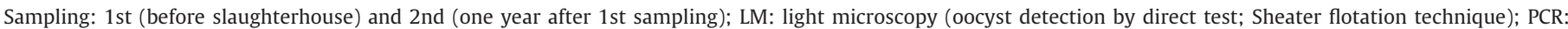
polymerase chain reaction; qPCR: quantitative real-time PCR (parasites $\mathrm{mL}^{-1}$ ).

parasite $\mathrm{mL}^{-1}$ in soil and non-ostrich fecal samples. A total of 25/38 (65.79\%) positive results were observed by PCR of ostrich brain samples $(24 / 38,63.17 \%)$ and the mouse bioassay $(14 / 38$, $36.84 \%)$, and was also confirmed by PCR $(8 / 14,57.14 \%$ peritoneal fluid; 6/14, 42.86\% brain). In the bioassay, 29/190 (15.26\%) mice died (average survival time $=49.42 \pm 14.75$ days; median parasite load $=2,230$ parasites $\mathrm{mL}^{-1}, \min =79$ parasites $\mathrm{mL}^{-1}$, $\max =54,829$ parasites $\mathrm{mL}^{-1}$ ) (Table 1 ). Out of the 29 positive mice, eight (27.58\%) 
were inoculated with material from ostriches presenting titer 8 , three $(10.34 \%)$ with titer 16 , ten $(34.48 \%)$ with titer 32 , three (10.34\%) with titer 64 and five (17.24\%) with titer 256 . A weak correlation was observed between the results of the mouse bioassay and PCR of ostrich brain samples ( $r s=0.2058$; p-value $=0.2152$ ). PCR presented higher sensitivity than the bioassay.

PCR-18 S rRNA results matched all PCR-529 bp results. The PCR products were confirmed by sequencing to be $100 \%$ homologous to Toxoplasma gondii repetitive DNA sequence (GenBank access number EF648168-1) and to Toxoplasma gondii $18 \mathrm{~S}$ ribosomal RNA gene, complete sequence (GenBank access number L37415.1). All 20 negative control animals produced negative results for all tests.

Genotyping was assayed for all PCR positive samples. The complete genotype was obtained just on Farm \#2 for ostrich samples, with two isolates from males, resulting in two atypical genotypes $\left(\mathrm{TgOsBr} 1=19,043\right.$ parasites $\mathrm{mL}^{-1}$, virulent, average survival time $=12$ days, $100 \%$ mortality; $\mathrm{TgOsBr} 2=54,829$ parasites $\mathrm{mL}^{-1}$, avirulent) (Table 1 ), previously reported to cause congenital toxoplasmosis in Brazilian patients (ToxoDB \#161 and \#206, respectively) (Table 5).

\section{Discussion}

It is very important that ostrich products are highly commercialized nowadays, and ostrich farming has received increased commercial attention, focusing on meat, leather, feathers and eggs (Figueiredo et al., 2004). For public health, the importance of toxoplasmosis is focused on meat production which is transmitted by the consumption of raw or undercooked meat (Kijlstra and Jongert, 2009). In the United States, the consumption of ostrich meat is increasing (Jones and Dubey, 2012). Despite the low risk (Dubey et al., 2000), it is important to note that toxoplasmosis still poses a risk to public health for humans consuming ostrich meat, as they are confirmed intermediate hosts of $T$. gondii (Kijlstra and Jongert, 2009).

Varying prevalence of $T$. gondii infection in ostriches was reported around the world. In the present study, ostriches reared for meat production presented a lower serological prevalence, $11.05 \%$, than Hove and Mukaratirwa (2005) found in slaughtered ostriches from Zimbabwe (48\%; 24/50), or Contente et al., (2009) and Almeida et al. (2013) found in ostriches reared for many purposes from Brazil (14.36\%; 18/195, and $17.39 \% ; 8 / 46$, respectively), but higher than El-Madawy and Metawea (2013) found in Egyptian ostriches reared for meat production, or Dubey et al. (2000) found in captive-ranched ostriches from Canada (2.9\%; 28/973), and Martínez-Díaz et al. (2002) found in slaughtered ostriches from Spain (0.9\%; 1/115). Some of the mentioned studies focused on meat production, others on the whole population. Contente et al., (2009) focused their research on animals for leather, feather or egg production, which represents a minimum or no risk for human infection, compared to meat consumption.

The antibody titers ranged from 16 to 256 . The same has been observed by Almeida et al. (2013), whereas Dubey et al. (2000) observed a range from 25 to 500 , and 16 to 16,384 by Contente et al., (2009). All animals were determined as having a chronic infection. T. gondii antibody titers remain detectable for months or years, and high titers can occur during continuous exposure to the source of infection (Gallas-Lindemann et al., 2013), i.e. oocysts on the ground.

The main nutrient in ostrich food is based on bulky feed by grazing on grass or by feeders filled with chopped forages. Additional ingestion of small stones is necessary for the mechanical digestion process of the most fibrous portion of food (Al-Nasser et al., 2003). In this way, an important factor to consider is the presence of domestic or wild felids, the definitive host, mainly in feed tanks, the water source provided, and paddocks that animals live. In this study, it was observed that cats, as well as rats, have access to the feed tanks. These cats can shed oocysts in their feces over the feed, which increases the risk of infection for these animals. In this way, humans can be infected by the ingestion of raw or undercooked meat of these infected animals, or direct ingestion of sporulated oocysts in the water.

The water tank was considered a significant risk factor for infection $(\mathrm{OR}=141.87$; $\mathrm{p}$-value $=0.000$ ), which reinforces the importance of water on toxoplasmosis transmission as highlighted by Dawson (2005), not only for ostriches but also for all production animals. This source of infection was not considered a risk for humans ( $\mathrm{p}$-value $>0.05$ ), but much more care should be taken in the treatment of water once it is also used for human consumption. Widespread environmental contamination with oocysts contributes to this. It is estimated that 140 million domestic and wild felids contribute to the fecal contamination of $T$. gondii oocysts in the United States (Hill and Dubey, 2013).

Oocysts were detected in three farms, but not in all sampled paddocks. As the positive animals lived in different paddocks in these farms, differential distribution and exposure to the oocysts is suggested. Most of the positive paddocks presented a low parasite load, which probably impaired the success of genotyping, but not for the transmission. One hypothesis for the presence of oocysts on the paddocks is the access of infected domestic or wild felids to the paddocks, which strongly contributes to dissemination of the infection by shedding oocysts to the soil (Gallas-Lindemann et al., 2013). Another hypothesis is the dissemination of sporulated oocysts by wild animals, e.g. armadillos, from contaminated to non-contaminated places, since the handlers reported the presence of armadillos and their burrows (also observed during the visits). Even at a low concentration, virulent $T$. gondii isolates can cause life-threatening disease in humans and animals and presents high importance to the public health (Da Silva et al., 2011).

No mouse bioassay from soil sampled produced in positive results. All animals survived and resulted in negative serology. Alternatively, the mouse bioassay for the ostrich brain samples resulted in different mortality rate. Different factors, i.e. parasite load, strain and infectious stage of the parasite, may interfere with the mortality rate (Pena et al., 2008). A high mortality rate in mice was expected in ostriches with high titers, but ostriches with a titer 256 presented just 25\% mortality (923-54,829 parasites $\mathrm{mL}^{-1}$ ). Analyzing the titer 64 (990-19,043 parasite $\mathrm{mL}^{-1}$ ), a 10\% mortality rate was observed, whereas there was $11.11 \%$ mortality rate in ostriches with titer 32 (parasite load $=1424-2063$ parasites $\mathrm{mL}^{-1}$ ). Ragozo et al. (2008) observed high mouse mortality rate (69.2\%) with tissues from sheep presenting higher titer (3200). The mouse survival time ranged from 3 (60\% mortality rate) to 12 days ( $100 \%$ mortality rate) (Table 1 ).

Just two complete genotypes of $T$. gondii were obtained from the ostrich tissue (TgOsBr1 and $\mathrm{TgOsBr} 2$ ) and mouse bioassay (TgOsBr2). Both typed isolates resulted in different survival times and mortality rates. The mouse bioassay is the most efficient method to obtain DNA from T. gondii, but direct tissue genotyping enhances the likelihood of obtaining molecular information on T. gondii (Cunha et al., 2016).

TgOsBr1 genotype matched TgCTBr01, -03, - 25 (ToxoDB \#206) isolated from newborn humans (congenital toxoplasmosis, CT) from Minas Gerais State, Brazil (Carneiro et al., 2013). Out of these, just TgCTBr03 was avirulent in the mouse bioassay, as with TgOsBr1. Until now, no species other than humans have been reported as having been infected with this genotype. This study emphasizes the importance of birds as sentinel animals for T. gondii infection, and about the consumption of raw or undercooked meat from ostriches. No association between both studies can be made, but the occurrence in humans, i.e. CT, and ostriches for human consumption supports the need to control the spread of the infection. 
Table 5

Genotypic profile and virulence for the T. gondii samples isolated from ostrich brain tissues.

\begin{tabular}{|c|c|c|c|c|c|c|c|c|c|c|c|c|c|c|c|}
\hline \multirow[t]{2}{*}{ Isolates } & \multirow[t]{2}{*}{ Virulence } & \multicolumn{11}{|c|}{ Genetic markers } & & \multirow[t]{2}{*}{ ToxoDB } & \multirow[t]{2}{*}{ Reference } \\
\hline & & SAG1 & $5^{\prime}-3^{\prime}$ SAG2 & alt-SAG2 & SAG3 & BTUB & GRA6 & c22-8 & c29-2 & L358 & PK1 & Apico & CS3 & & \\
\hline TgOsBr1 & Avirulent & $\mathrm{u}-1$ & I & II & III & III & III & II & III & I & III & I & $\mathrm{u}-1$ & \#206 & Carneiro et al. (2013) \\
\hline TgOsBr2 & Virulent & I & III & III & III & III & III & I & I & nd & III & I & $\mathrm{u}-1$ & \#161 & Soares et al. (2011) ${ }^{\mathrm{b}}$ \\
\hline
\end{tabular}

$\mathrm{u}-1$ is a new allele different from the type I, II and III clonal alleles; nd: no data.

a $\operatorname{TgCTBr} 1,3,25$ (100\% match, excluding CS3 marker).

b $\mathrm{TgCkBr} 199$ (90\% match, excluding CS3 marker).

On other hand, TgOsBr2 matched in 90\% the genotype TgCkBr199 (ToxoDB \#161), excluding CS3 marker, isolated from free-range chickens also from Mato Grosso do Sul State, Brazil (Soares et al., 2011). The only gap was observed in the L358 marker; no amplification product was observed, whereas $\mathrm{TgCkBr} 199$ presented allele type III to this marker. No other isolate reported in the literature presented a close genotype to TgOsBr2. In this way, TgOsBr2 may match $100 \%$ to $\mathrm{TgCkBr} 199$ or may be considered a new unique genotype obtained in ostriches from Brazil. Interestingly, TgOsBr2 was virulent ( $100 \%$ lethal; survival time $=12$ days), different from $\mathrm{TgCkBr} 199$, which was avirulent.

Another important difference observed concerns the CS3 marker, with u-1 (TgOsBr2) and u-2 (TgCkBr199) alleles. Pena et al. (2008) observed that isolates presenting alleles I or II to the CS3 marker were more commonly virulent, with approximately $80 \%$ mortality. As this marker may be related to the virulence (Pena et al., 2008), the difference in this marker may explain different phenotypes in the mouse bioassay, but researchers should be careful in considering this. This marker should be more explored and linked to other variants, including phenotypic events, to state if the isolate is considered virulent or not. Also, a new unique genotype may explain this difference, as $\mathrm{TgCkBr} 199$ has only been isolated from Brazilian chickens, which might support the high diversity of the parasite in the population isolated from Brazil.

Corroborating these data, Central and South America possess a high degree of genetic diversity, compared to the archetypes I, II and III, previously isolated in Europe and North America (Su et al., 2006, 2012; Pena et al., 2008; Da Silva et al., 2011; Soares et al., 2011; Carneiro et al., 2013; Shwab et al., 2014). Only a few genotypes are dominant in the northern hemisphere, which is in stark contrast to the southern hemisphere where hundreds of genotypes coexist with none being notably dominant (Shwab et al., 2014). This diversity is much more visible when comparing isolates from North America (low diversity) and those from Central and South America (high diversity) (Pena et al., 2008; Dubey et al., 2011; Khan et al., 2011; Shwab et al., 2014), with no clear dominance of any genotype even though a few have relatively higher frequencies (Shwab et al., 2014).

Thus, this study is the first study to determine the prevalence of $T$. gondii infection in ostriches, by serological, isolation and molecular tests, and determine its association with risk factors present in farms in which they were bred, and determine a potential new atypical genotype, corroborating with the high genotypic variability of $T$. gondii in Brazilian production animals already reported in other studies, and another atypical genotype previously reported in newborn humans with congenital toxoplasmosis.

\section{Conclusions}

These findings support the occurrence of $T$. gondii in slaughtered ostriches from Brazil, which should be considered an important source of infection for humans that consume ostrich meat. This study also confirms the presence of a genotype in ostriches that was previously reported to cause congenital toxoplasmosis in humans, and the genotypic variability in Brazilian isolates with, possibly, a new atypical type detected. Ostriches are important hosts for the epidemiological chain of toxoplasmosis due to being production animals and a source of protein for human consumption. In this way, ostriches can also be considered important sentinels for environmental contamination of $T$. gondii.

\section{Conflict of interest}

The authors report no conflict of interest in the present study.

\section{Acknowledgements}

We would like to thank the São Paulo Research Foundation (FAPESP) for the Postdoctoral fellowship (\#2009/14207-0) and the financial support (\#2011/01279-3), and the São Paulo State University for the logistical support.

\section{References}

Acha, P., Szyfres, B., 2003. Zoonosis y enfermedades transmisibles communes al hombre y a los animals, 3rd ed. Organización Panamericana de la Salud, Geneva, Switzerland, pp. 443.

Al-Nasser, A., Al-Khalaifa, H., Holleman, K., Al-Ghalaf, W., 2003. Ostrich production in the arid environment of Kwait. J. Arid Environ. 54, 219-224.

Almeida, A.B., Krindges, M.M., de Barros, L.D., Garcia, J.L., Camillo, G., Vogel, F.S., Araujo, D.N., Stefani, L.M., da Silva, A.S., 2013. Occurrence of antibodies to Toxoplasma gondii in rheas (Rhea americana) and ostriches (Struthio camelus) from farms of different Brazilian regions. Rev. Bras. Parasitol. Vet. 22, 437-439.

CDC, 2002. Epi Info, version v.3.5.4 (Atlanta, GA, Center for Disease Control and Prevention).

Carneiro, A.C., Andrade, G.M., Costa, J.G., Pinheiro, B.V., Vasconcelos-Santos, D.V., Ferreira, A.M., Su, C., Januario, J.N., Vitor, R.W., 2013. Genetic characterization of Toxoplasma gondii revealed highly diverse genotypes for isolates from newborns with congenital toxoplasmosis in southeastern Brazil. J. Clin. Microbiol. 51, 901-907.

Casartelli-Alves, L., Amendoeira, M.R., Boechat, V.C., Ferreira, L.C., Carreira, J.C., Nicolau, J.L., de Freitas Trindade, E.P., de Barros Peixoto, J.N., Magalhaes Mde, A., de Oliveira Rde, V., Schubach, T.M., Menezes, R.C., 2015. Mapping of the environmental contamination of Toxoplasma gondii by georeferencing isolates from chickens in an endemic area in Southeast Rio de Janeiro State, Brazil. Geospat. Health 10, 311.

Cavalcante, A.C.R., Ferreira, A.M., Melo, M.N., Fux, B., Brandão, G.P., Vitor, R.W.A., 2007. Virulence and molecular characterization of Toxoplasma gondii isolated from goats in Ceará, Brazil. Small Rumin. Res. 69, 79-82.

Contente, A.P.A., Domingues, P.F., Silva, R.C., 2009. Prevalence of Toxoplasma gondii antibodies in ostriches (Struthio camelus) from commercial breeding facilities in the state of São Paulo, Brazil. Braz. J. Vet. Res. Anim. Sci. 46, 175-180.

Cunha, M.M., Carneiro, A.C., Costa, J.G., Vitor, R.W., 2016. Genotyping of Toxoplasma gondii directly from human and animal biological samples: from partial genotypes to a new genotype. J. Parasitol. 102, 157-160.

Da Silva, R.C., Su, C., Langoni, H., 2009. First identification of Sarcocystis tenella (Railliet, 1886) Moule, 1886 (Protozoa: Apicomplexa) by PCR in naturally infected sheep from Brazil. Vet. Parasitol. 165, 332-336.

Da Silva, R.C., Langoni, H., Su, C., Da Silva, A.V., 2011. Genotypic characterization of Toxoplasma gondii in sheep from Brazilian slaughterhouses: new atypical genotypes and the clonal type II strain identified. Vet. Parasitol. 175, 173-177.

Dannemann, B.R., Vaughan, W.C., Thulliez, P., Remington, J.S., 1990. Differential agglutination test for diagnosis of recently acquired infection with Toxoplasma gondii. J. Clin. Microbiol. 28, 1928-1933.

Dawson, D., 2005. Foodborne protozoan parasites. Int. J. Food Microbiol. 103, 207-227.

Desmonts, G., Remington, J.S., 1980. Direct agglutination test for diagnosis of Toxoplasma infection: method for increasing sensitivity and specificity. J. Clin. Microbiol. 11, 562-568.

Dubey, J.P., Beattie, C.P., 1988. Toxoplasmosis of Animals and Man. CRC Press Inc., Boca Raton, FL. 
Dubey, J.P., Scandrett, W.B., Kwok, O.C., Gajadhar, A.A., 2000. Prevalence of antibodies to Toxoplasma gondii in ostriches (Struthio camelus). J. Parasitol. 86, 623-624.

Dubey, J.P., Su, C., Cortes, J.A., Sundar, N., Gomez-Marin, J.E., Polo, L.J., Zambrano, L., Mora, L.E., Lora, F., Jimenez, J., Kwok, O.C., Shen, S.K., Zhang, X., Nieto, A., Thulliez, P., 2006a. Prevalence of Toxoplasma gondii in cats from Colombia, South America and genetic characterization of T. gondii isolates. Vet. Parasitol. $141,42-47$.

Dubey, J.P., Sundar, N., Pineda, N., Kyvsgaard, N.C., Luna, L.A., Rimbaud, E., Oliveira, J.B., Kwok, O.C., Qi, Y., Su, C., 2006b. Biologic and genetic characteristics of Toxoplasma gondii isolates in free-range chickens from Nicaragua, Central America. Vet. Parasitol. 142, 47-53.

Dubey, J.P., Cortes-Vecino, J.A., Vargas-Duarte, J.J., Sundar, N., Velmurugan, G.V., Bandini, L.M., Polo, L.J., Zambrano, L., Mora, L.E., Kwok, O.C., Smith, T., Su, C., 2007. Prevalence of Toxoplasma gondii in dogs from Colombia, South America and genetic characterization of T. gondii isolates. Vet. Parasitol. 145, 45-50.

Dubey, J.P., Rajendran, C., Ferreira, L.R., Martins, J., Kwok, O.C., Hill, D.E., Villena, I., Zhou, H., Su, C., Jones, J.L., 2011. High prevalence and genotypes of Toxoplasma gondii isolated from goats from a retail meat store, destined for human consumption in the USA. Int. J. Parasitol. 41, 827-833.

Dubey, J.P., Laurin, E., Kwowk, O.C., 2016. Validation of the modified agglutination test for the detection of Toxoplasma gondii in free-range chickens by using cat and mouse bioassay. Parasitology 143, 314-319.

Dubey, J.P., 1995. Duration of immunity to shedding of Toxoplasma gondii oocysts by cats. J. Parasitol. 81, 410-415.

Dubey, J.P., 1998. Refinement of pepsin digestion method for isolation of Toxoplasma gondii from infected tissues. Vet. Parasitol. 74, 75-77.

Edvinsson, B., Lappalainen, M., Evengard, B., Toxoplasmosis, E.S.G.f., 2006. Real-time PCR targeting a 529-bp repeat element for diagnosis of toxoplasmosis. Clin. Microbiol. Infect. 12, 131-136.

El-Madawy, S.R., Metawea, F.Y., 2013. Serological assays and PCR for detection of Toxoplasma gondii infection in an ostrich farm at Ismailia Provine, Egypt. IOSR J. Agric. Vet. Sci. 2, 56-60.

Figueiredo, F.R., Pineiro, L.A.S., Domingues, J.S., 2004. Avestruz: situação organizacional. Avicult. Ind. 1, 25-28.

Freyre, A., Dubey, J.P., Smith, D.D., Frenkel, J.K., 1989. Oocyst-induced Toxoplasma gondii infections in cats. J. Parasitol. 75, 750-755.

Gallas-Lindemann, C., Sotiriadou, I., Mahmoodi, M.R., Karanis, P., 2013. Detection of Toxoplasma gondii oocysts in different water resources by Loop Mediated Isothermal Amplification (LAMP). Acta Trop. 125, 231-236.

Hill, D.E., Dubey, J.P., 2013. Toxoplasma gondii prevalence in farm animals in the United States. Int. J. Parasitol. 43, 107-113.

Homan, W.L., Vercammen, M., De Braekeleer, J., Verschueren, H., 2000. Identification of a 200 - to 300 -fold repetitive 529 bp DNA fragment in Toxoplasma gondii, and its use for diagnostic and quantitative PCR. Int. J. Parasitol. 30, 69-75.

Hove, T., Mukaratirwa, S., 2005. Seroprevalence of Toxoplasma gondii in farm-reared ostriches and wild game species from Zimbabwe. Acta Trop. 94, $49-53$

Jones, J.L., Dubey, J.P., 2012. Foodborne toxoplasmosis. Clin. Infect. Dis. 55, 845-851.

Khan, A., Taylor, S., Su, C., Mackey, A.J., Boyle, J., Cole, R., Glover, D., Tang, K., Paulsen, I.T., Berriman, M., Boothroyd, J.C., Pfefferkorn, E.R., Dubey, J.P., Ajioka J.W., Roos, D.S., Wootton, J.C., Sibley, L.D., 2005. Composite genome map and recombination parameters derived from three archetypal lineages of Toxoplasma gondii. Nucleic Acids Res. 33, 2980-2992.
Khan, A., Dubey, J.P., Su, C., Ajioka, J.W., Rosenthal, B.M., Sibley, L.D., 2011. Genetic analyses of atypical Toxoplasma gondii strains reveal a fourth clonal lineage in North America. Int. J. Parasitol. 41, 645-655.

Kijlstra, A., Jongert, E., 2009. Toxoplasma-safe meat: close to reality? Trends Parasitol. 25, 18-22.

Li, Y.N., Nie, X., Peng, Q.Y., Mu, X.Q., Zhang, M., Tian, M.Y., Min, S.J., 2015. Seroprevalence and genotype of Toxoplasma gondii in pigs, dogs and cats from Guizhou province, Southwest China. Parasites Vectors 8, 214.

Maciel, B.M., Moura, R.L., Carvalho, F.S., Costa, E.A., Albuquerque, G.R., 2014. Identification and genetic characterization of a new Brazilian genotype of Toxoplasma gondii from sheep intended for human consumption. Parasitol. Int. 63, 567-570.

Martínez-Díaz, R.A., Simmons, B., Ponce-Gordo, F., 2002. Serologic screening to detect Toxoplasma gondii antibodies in farmed ostriches (Struthio camelus) in Spain. Rev. Iberica Parasitol. 62, 69-71.

Montoya, J.G., Berry, A., Rosso, F., Remington, J.S., 2007. The differential agglutination test as a diagnostic aid in cases of toxoplasmic lymphadenitis. J. Clin. Microbiol. 45, 1463-1468.

Pena, H.F., Gennari, S.M., Dubey, J.P., Su, C., 2008. Population structure and mouse-virulence of Toxoplasma gondii in Brazil. Int. J. Parasitol. 38, 561-569.

Ragozo, A.M., Yai, R.L., Oliveira, L.N., Dias, R.A., Dubey, J.P., Gennari, S.M., 2008. Seroprevalence and isolation of Toxoplasma gondii from sheep from Sao Paulo state, Brazil. J. Parasitol. 94, 1259-1263.

Ruiz, A., Frenkel, J.K., 1980. Intermediate and transport hosts of Toxoplasma gondii in Costa Rica. Am. J. Trop. Med. Hyg. 29, 1161-1166.

Sheater, A.L., 1923. The detection of intestinal protozoa and mange parasites by a flotation technique. J. Comp. Pathol. 36, 266-275.

Shwab, E.K., Zhu, X.Q., Majumdar, D., Pena, H.F., Gennari, S.M., Dubey, J.P., Su, C., 2014. Geographical patterns of Toxoplasma gondii genetic diversity revealed by multilocus PCR-RFLP genotyping. Parasitology 141, 453-461.

Soares, R.M., Silveira, L.H., da Silva, A.V., Ragozo, A., Galli, S., Lopes, E.G., Gennari, S.M., de Jesus Pena, H.F., 2011. Genotyping of Toxoplasma gondii isolates from free range chickens in the Pantanal area of Brazil. Vet. Parasitol. 178, 29-34.

Su, C., Zhang, X., Dubey, J.P., 2006. Genotyping of Toxoplasma gondii by multilocus PCR-RFLP markers: a high resolution and simple method for identification of parasites. Int. J. Parasitol. 36, 841-848.

Su, C., Khan, A., Zhou, P., Majumdar, D., Ajzenberg, D., Darde, M.L., Zhu, X.Q., Ajioka J.W., Rosenthal, B.M., Dubey, J.P., Sibley, L.D., 2012. Globally diverse Toxoplasma gondii isolates comprise six major clades originating from a small number of distinct ancestral lineages. Proc. Natl. Acad. Sci. U. S. A. 109, 5844-5849,

Tenter, A.M., Heckeroth, A.R., Weiss, L.M., 2000. Toxoplasma gondii: from animals to humans. Int. J. Parasitol. 30, 1217-1258.

Thulliez, P., Remington, J.S., Santoro, F., Ovlaque, G., Sharma, S., Desmonts, G., 1986. Une nouvelle réaction d'agglutination pour le diagnostic du stade évolutif de la toxoplasmose acquise. Pathol. Biol. 34, 173-177.

Triola, M.F., 2005. Introdução à estatística, 9th ed. LTC, Rio de Janeiro, pp. 682

Wang, L., Shen, J.L., 2013. Research progress on genotype and genotype-associated pathogenesis of Toxoplasma gondii. Chin. J. Parasitol. 31, 319-324. 